\title{
Specialized metabolites from the aerial parts of Centaurea polyclada DC.
}

\author{
Serdar Demir ${ }^{\text {a }}$, Canan Karaalp ${ }^{\mathrm{a}}$, Erdal Bedir ${ }^{\mathrm{b}, *}$ \\ a Department of Pharmaceutical Botany, Faculty of Pharmacy, Ege University, 35100, Bornova, Izmir, Turkey \\ ${ }^{\mathrm{b}}$ Department of Bioengineering, Faculty of Engineering, Izmir Institute of Technology, 35430, Urla, Izmir, Turkey
}

\section{A R T I C L E I N F O}

\section{Article history:}

Received 25 April 2017

Received in revised form

20 June 2017

Accepted 12 July 2017

\section{Keywords:}

Centaurea polyclada

Asteraceae

Specialized metabolite

Sesquiterpene

Amino acid conjugate

L-proline

\begin{abstract}
A B S T R A C T
The genus Centaurea L. (Asteraceae) is represented by 200 taxa in the flora of Turkey and several Centaurea species are used as herbal remedies against different conditions. Previous phytochemical investigations on this genus generally revealed the isolation of sesquiterpene lactones and flavonoid derivatives. In our continuous search on Centaurea genus, a phytochemical study was performed on Centaurea polyclada DC., an endemic of West Anatolia.

Previously undescribed two sesquiterpene-amino acid conjugates, an elemane and an eudesmane derivative were isolated from the aerial parts of Centaurea polyclada, together with eight known compounds; two elemane derivatives, three flavonoids, a lignan, a phenolic glucoside and a phenylpropanoid glucoside. Structural elucidation of the compounds was based on spectroscopic evidence, including 1D and 2D NMR and high-resolution mass spectrometry, chemical degradation results and reference data comparison. Sesquiterpene-amino acid conjugates are representatives of an unusual group of sesquiterpenes, and elemane-amino acid conjugates are herein reported for the first time in nature.
\end{abstract}

๑) 2017 Elsevier Ltd. All rights reserved.

\section{Introduction}

Centaurea polyclada DC. (Asteraceae) is an endemic, profusely branched, perennial plant and naturally distributed in West Anatolia (Uysal, 2012; Wagenitz, 1975). The genus Centaurea L. is represented by 200 taxa in the flora of Turkey and several Centaurea species are used as herbal remedies against inflammatory conditions, such as abscesses, asthma, hemorrhoids, peptic ulcer, malaria, common colds, stomach upset and abdominal pain (Akkol et al., 2009; Ozcelik et al., 2009). Previous studies have confirmed that this genus is a source of novel bioactive compounds. Phytochemical investigations on this genus generally revealed the isolation of sesquiterpene lactones, flavonoids, phenyl propanoids, lignans and phenolic compounds (Astari et al., 2013; Baykan-Erel et al., 2010; Bruno et al., 2013; Cardona et al., 1997, 1991; Erel et al., 2011; Gulcemal et al., 2010; Karamenderes et al., 2007a, 2007b; Skaltsa et al., 1999). Composition of the essential oil of Centaurea polyclada was previously reported (Erel et al., 2013). In our continuous search on Centaurea species, a phytochemical study was performed on Centaurea polyclada DC.

\footnotetext{
* Corresponding author.

E-mail addresses: erdalbedir@iyte.edu.tr, erdalbedir@gmail.com (E. Bedir).
}

Fractionation of $\mathrm{CHCl}_{3}$ and $n$-BuOH extracts from the aerial parts of $C$. polyclada led to the isolation of four previously undescribed specialized metabolites (1-4) together with eight known compounds (5-12). Herein, the isolation and structural elucidation of compounds $\mathbf{1 - 4}$ are described. ${ }^{1} \mathrm{H}$ and ${ }^{13} \mathrm{C}$-NMR data of compounds $\mathbf{5}$ and $\mathbf{6}$ are also provided (Tables 1 and 2).

\section{Results and discussion}

$\mathrm{CHCl}_{3}$ and $n$-BuOH extracts from the aerial parts of $C$. polyclada was subjected to a series of column chromatographic separation steps. Purification studies led to the isolation of previously undescribed two elemane sesquiterpene-amino acid conjugates ( $\mathbf{1}$ and 2) together with an elemane derivative (3) and an eudesmane type sesquiterpene (4). The known compounds; two elemane derivatives; $6 \alpha, 8 \alpha, 15$-trihydroxyelema-1,3,11(13)-trien-12-oic acid (5) (Cardona et al., 1992) and its methyl ester (6) (Cardona et al., 1992), three flavonoids; salvigenin (7) (Salan et al., 2001), eupatorin (8) and 3'-methoxy eupatorin (9) (Salan et al., 2001), a lignan; arctiin (10) (Shoeb et al., 2004), a phenolic glucoside; tachioside (11) (Liu et al., 2013) and a phenylpropanoid glucoside; syringin (12) (Konuklugil and Bahadir, 2004) were identified by comparison of their spectroscopic data with literature values (Fig. 1). Herein, the 
Table 1

${ }^{1} \mathrm{H}$ NMR data of compounds $\mathbf{1}-\mathbf{6}\left[400 \mathrm{MHz}, \mathrm{CD}_{3} \mathrm{OD}, \delta_{\mathrm{H}}(\mathrm{J} \text { in } \mathrm{Hz})\right]^{\mathrm{a}}$

\begin{tabular}{|c|c|c|c|c|c|c|c|c|c|c|c|c|}
\hline Position & 1 & & 2 & & 3 & & 4 & & 5 & & 6 & \\
\hline 1 & 5.84 & dd $(17.2 / 10.8)$ & 5.73 & dd $(17.2 / 11.2)$ & 5.77 & dd $(18 / 10.8)$ & 3.28 & dd $(11.2 / 4.4)$ & 5.76 & dd $(18 / 10.4)$ & 5.76 & dd (18/10.4) \\
\hline \multirow[t]{2}{*}{2} & 5.01 & $\mathrm{~d}(10.8)$ & 4.87 & $\mathrm{~d}(11.2)^{\mathrm{b}}$ & 4.94 & $\mathrm{~d}(10.8)$ & 1.77 & $\mathrm{~m}$ & 4.92 & $\mathrm{~d}(10.4)$ & 4.93 & $\mathrm{~d}(10.4)$ \\
\hline & 4.99 & $\mathrm{~d}(17.2)$ & 4,89 & $\mathrm{~d}(17.2)$ & 4,92 & $d(18.0)$ & 1.67 & ddd (12.8/4.4) & 4.91 & $\mathrm{~d}(18)$ & 4.92 & $\mathrm{~d}(18)$ \\
\hline \multirow[t]{2}{*}{3} & 5.39 & brs & 5.34 & brs & 5.35 & brs & 1.51 & $\mathrm{~m}^{\mathrm{b}}$ & 5.33 & brs & 5.34 & brs \\
\hline & 4.98 & brs & 4.96 & brs & 4.97 & brs & 1.55 & $\mathrm{~m}^{\mathrm{b}}$ & 4.94 & brs & 4.93 & brs \\
\hline 4 & & & & & & & 2.19 & $\mathrm{~m}^{\mathrm{b}}$ & & & & \\
\hline 5 & 2.34 & $\mathrm{~d}(12)$ & 1.89 & $\mathrm{~d}(10.8)$ & 1.92 & $\mathrm{~d}(10.8)$ & 1.52 & $\mathrm{~m}^{\mathrm{b}}$ & 1.87 & $\mathrm{~d}(10.8)$ & 1.85 & $\mathrm{~d}(10.8)$ \\
\hline 6 & 4.56 & dd $(11.6 / 10.8)$ & 3.90 & $\mathrm{~m}^{\mathrm{b}}$ & 4.26 & $\mathrm{t}(10.4)$ & 3.87 & $\mathrm{t}(10.4)$ & 4.10 & dd $(10.4 / 10)$ & 4.13 & dd $(10.8 / 10.4)$ \\
\hline 7 & 2.03 & ddd (11.6/10.8) & 1.80 & $\mathrm{~m}$ & 2.64 & $\mathrm{t}(10.8)$ & 2.23 & $\mathrm{t}(10.4)$ & 2.33 & dd $(10.4 / 10)$ & 2.32 & $\mathrm{t}(10.4)$ \\
\hline 8 & 4.08 & $\operatorname{td}(10.8 / 4.4)$ & 3.93 & $\mathrm{~m}^{\mathrm{b}}$ & 5.53 & $\operatorname{td}(11.2 / 4.4)$ & 4.07 & $\operatorname{td}(10.8 / 4.8)$ & 4.08 & $\operatorname{td}(10.4 / 4)$ & 4.11 & $\operatorname{td}(10.8 / 4.4)$ \\
\hline \multirow[t]{2}{*}{9} & 1.80 & dd $(13.2 / 4.4)$ & 1.69 & dd $(12.4 / 4)$ & 1.86 & dd $(12.4 / 4.4)$ & 2.27 & dd $(12.4 / 4.8)$ & 1.73 & dd $(12.4 / 4)$ & 1.74 & dd $(12.8 / 4.4)$ \\
\hline & 1.61 & dd $(13.2 / 10.8)$ & 1.50 & dd $(12.4 / 12)$ & 1.62 & dd $(12 / 11.6)$ & 1.09 & dd $(12.4 / 11.6)$ & 1.50 & $\mathrm{t}(12.0)$ & 1.50 & $\mathrm{t}(12)$ \\
\hline \multicolumn{13}{|l|}{10} \\
\hline 11 & 3.30 & $\mathrm{~m}^{\mathrm{b}}$ & 3.25 & $\mathrm{~m}^{\mathrm{b}}$ & & & & & & & & \\
\hline \multicolumn{13}{|l|}{12} \\
\hline \multirow[t]{2}{*}{13} & 3.66 & dd (13.2/5.2) & 3.88 & $\mathrm{~m}^{\mathrm{b}}$ & 6.28 & brs & 6.33 & $\mathrm{~d}(1.2)$ & 6.22 & brs & 6.34 & $\mathrm{~d}(1.6)$ \\
\hline & 3.44 & dd $(13.2 / 8)$ & 3.10 & $\mathrm{~m}^{\mathrm{b}}$ & 5.70 & brs & 5.70 & $\mathrm{~d}(1.2)$ & 5.62 & brs & 5.75 & $\mathrm{~d}(1.6)$ \\
\hline 14 & 1.13 & $\mathrm{~s}$ & 1.05 & $\mathrm{~s}$ & 1.21 & s & 0.95 & $\mathrm{~s}$ & 1.11 & $\mathrm{~s}$ & 1.13 & $\mathrm{~s}$ \\
\hline \multirow[t]{2}{*}{15} & 4.03 & $d(15.2)$ & 3.98 & $\mathrm{~d}(14.4)$ & 4.01 & d (14.8) & 9.31 & $\mathrm{~d}(5.2)$ & 3.99 & d (14.8) & 3.99 & $\mathrm{~d}(14.4)$ \\
\hline & 3.93 & $\mathrm{~d}(15.2)$ & 3.88 & $\mathrm{~d}(14.4)^{\mathrm{b}}$ & 3.91 & $d(14.8)$ & & & 3.89 & $d(14.8)$ & 3.89 & $\mathrm{~d}(14.4)$ \\
\hline \multicolumn{13}{|l|}{$1^{\prime}$} \\
\hline $2^{\prime}$ & 3.99 & dd $(9.2 / 4)$ & 3.87 & $\mathrm{~m}^{\mathrm{b}}$ & & & & & & & & \\
\hline \multirow[t]{2}{*}{$3^{\prime}$} & 2.44 & $\mathrm{~m}$ & 2.40 & $\mathrm{~m}$ & 6.30 & qd $(7.2 / 1.2)$ & & & & & & \\
\hline & 2.26 & $\mathrm{~m}$ & 2.20 & $\mathrm{~m}$ & & & & & & & & \\
\hline \multirow[t]{2}{*}{$4^{\prime}$} & 2.12 & $\mathrm{~m}$ & 2.10 & $\mathrm{~m}$ & 1.97 & dd (7.2/1.2) & & & & & & \\
\hline & 1.93 & $\mathrm{~m}$ & 1.97 & $\mathrm{~m}$ & & & & & & & & \\
\hline \multirow[t]{2}{*}{$5^{\prime}$} & 3.78 & $\mathrm{~m}$ & 3.75 & $\mathrm{~m}$ & 4.16 & dd (13.6/1.2) & & & & & & \\
\hline & 3.24 & $\mathrm{~m}^{\mathrm{b}}$ & 3.10 & $\mathrm{~m}^{\mathrm{b}}$ & 4.10 & dd (13.6/1.2) & & & & & & \\
\hline$-\mathrm{OCH}_{3}$ & & & & & & & 3.74 & S & & & 3.76 & $\mathrm{~s}$ \\
\hline
\end{tabular}

a Assignments of ${ }^{1} \mathrm{H}$ and ${ }^{13} \mathrm{C}$ NMR data are based on ${ }^{1} \mathrm{H}-{ }^{1} \mathrm{H}$ COSY, HSQC and HMBC experiments.

b Overlapping signals.

Table 2

${ }^{13} \mathrm{C}$ NMR data of compounds $\mathbf{1}-\mathbf{6}\left[100 \mathrm{MHz}, \mathrm{CD}_{3} \mathrm{OD}, \delta_{\mathrm{C}}(\mathrm{ppm})\right] .^{\mathrm{a}}$

\begin{tabular}{llllllll}
\hline Position & Type & $\mathbf{1}$ & $\mathbf{2}$ & $\mathbf{3}$ & $\mathbf{4}$ & $\mathbf{5}$ & $\mathbf{6}$ \\
\hline 1 & $\mathrm{CH}$ & 148.4 & 149.1 & 148.5 & 78.3 & 149.2 & 149.0 \\
2 & $\mathrm{CH}_{2}$ & 112.5 & 111.3 & 111.8 & 28.8 & 111.3 & 111.4 \\
3 & $\mathrm{CH}_{2}$ & 112.9 & 112.4 & 112.0 & 25.4 & 11.9 & 112.0 \\
4 & $\mathrm{C}$ & 146.2 & 148.5 & 148.1 & $49.9(\mathrm{CH})$ & 148.5 & 148.3 \\
5 & $\mathrm{CH}$ & 51.6 & 57.1 & 56.6 & 53.0 & 56.7 & 56.7 \\
6 & $\mathrm{CH}$ & 80.7 & 70.5 & 72.0 & 71.4 & 72.5 & 71.6 \\
7 & $\mathrm{CH}$ & 58.0 & 55.1 & 56.9 & 61.6 & 59.7 & 60.6 \\
8 & $\mathrm{CH}$ & 67.6 & 67.4 & 72.0 & 68.1 & 68.9 & 68.2 \\
9 & $\mathrm{CH}$ & 49.8 & 49.8 & 44.8 & 46.5 & 49.8 & 49.6 \\
10 & $\mathrm{C}$ & 43.0 & 41.0 & 41.2 & 39.8 & 41.0 & 41.0 \\
11 & $\mathrm{C}$ & $44.5(\mathrm{CH})$ & $41.3(\mathrm{CH})$ & 140.8 & 139.8 & 142.5 & 140.2 \\
12 & $\mathrm{C}$ & 176.8 & 180.3 & 170.4 & 168.5 & 166.8 & 168.7 \\
13 & $\mathrm{CH}_{2}$ & 56.6 & 57.3 & 128.7 & 130.0 & 125.4 & 129.4 \\
14 & $\mathrm{CH}_{3}$ & 19.1 & 19.4 & 19.1 & 12.6 & 19.4 & 19.4 \\
15 & $\mathrm{CH}_{2}$ & 66.8 & 67.7 & 67.6 & $204.9(\mathrm{CH})$ & 67.7 & 67.6 \\
$1^{\prime}$ & $\mathrm{C}$ & 174.0 & 173.7 & 167.5 & & & \\
$2^{\prime}$ & $\mathrm{CH}^{\prime}$ & 72.0 & 72.1 & $133.6(\mathrm{C})$ & & & \\
$3^{\prime}$ & $\mathrm{CH}_{2}$ & 30.5 & 30.1 & $139.1(\mathrm{CH})$ & & & \\
$4^{\prime}$ & $\mathrm{CH}_{2}$ & 24.8 & 24.6 & $15.7(\mathrm{CH})$ & & & \\
$5^{\prime}$ & $\mathrm{CH}_{2}$ & 57.1 & 53.6 & 63.9 & & & 52.1 \\
$-\mathrm{OCH}_{3}$ & & & & & 52.0 & & \\
\hline
\end{tabular}

a Assignments of ${ }^{1} \mathrm{H}$ and ${ }^{13} \mathrm{C}$ NMR data are based on ${ }^{1} \mathrm{H}-{ }^{1} \mathrm{H}$ COSY, HSQC and HMBC experiments.

isolation and structural elucidation of compounds 1-4 are described. NMR data for compounds $\mathbf{5}$ and $\mathbf{6}$ were also provided.

Compound 1 was obtained as a yellowish gum. QTOF-MS analysis displayed protonated and deprotonated molecular ion peaks at $380.2028[\mathrm{M}+\mathrm{H}]^{+}$and $378.1921[\mathrm{M}-\mathrm{H}]^{-}$for positive and negative modes, suggesting a molecular formula of $\mathrm{C}_{20} \mathrm{H}_{29} \mathrm{NO}_{6}$. Of the seven degrees of unsaturation deduced from the molecular formula, four were present as multiple bonds including two carbonyl carbons $\left(\delta_{\mathrm{C}}\right.$ $176.8,174.0,148.4,146.2,112.9$ and 112.5). Initial inspection of the
${ }^{1} \mathrm{H},{ }^{13} \mathrm{C}-\mathrm{NMR}$ and HSQC spectra of $\mathbf{1}$ revealed a mono-substituted olefinic system $\left(\delta_{\mathrm{H}} 5.84,5.01\right.$ and $4.99 ; \delta_{\mathrm{C}} 148.4$ and 112.5$)$ suggesting an isolated ethenyl group, a pair of broad singlet protons $\left(\delta_{\mathrm{H}}\right.$ 5.39 and 4.98 , each $1 \mathrm{H} ; \delta_{\mathrm{C}} 112.9$ ) implying an exocyclic double bond, two geminal oxymethylene protons as $A B$ system doublets $\left(\delta_{\mathrm{H}} 4.03\right.$ and $\left.3.93 ; \delta_{\mathrm{C}} 66.8\right)$, two oxymethine groups $\left(\delta_{\mathrm{H}} 4.56\right.$ and $4.08 ; \delta_{C} 80.7$ and 67.6$)$ and a tertiary methyl signal $\left(\delta_{H} 1.13,3 \mathrm{H} ; \delta_{C}\right.$ 19.1) (Fig. 1, Tables 1 and 2). The covalent connectivity of 1 was established by thorough analysis of the COSY and HSQC spectra. The association of partial structures and assignment of quaternary carbon atoms were completed by means of long-range correlations in the HMBC spectrum.

Based on the COSY and HMBC correlations (Fig. 2), an isolated framework was readily deduced that was consistent with proline moiety $\left(\delta_{\mathrm{H}} 3.99\right.$, dd, $J=9.2,4.0 \mathrm{~Hz}, \mathrm{H}-2^{\prime} ; 2.44$ and $2.26, \mathrm{~m}, \mathrm{H}_{2}-3^{\prime}$; 2.12 and $1.93, \mathrm{~m}, \mathrm{H}_{2}-4^{\prime} ; 3.78$ and $3.24, \mathrm{~m}, \mathrm{H}_{2}-5^{\prime} ; \delta_{\mathrm{C}} 174.0, \mathrm{C}-1^{\prime} ; 72.0$, C-2'; 30.5, C-3'; 24.8, C-4' and 57.1, C-5') (Matsuda et al., 2000). After subtracting 5 carbon resonances of the proline residue and two degrees of unsaturation, the remaining 15 signals were attributable to a bicyclic sesquiterpene skeleton with three multiple bonds.

A detailed examination of the ${ }^{1} \mathrm{H}$ NMR spectrum of $1\left(\delta_{\mathrm{H}} 5.84\right.$, $\mathrm{dd}, J=17.2,10.8 \mathrm{~Hz}, \mathrm{H}-1 ; 5.01, \mathrm{~d}, J=10.8 \mathrm{~Hz}$ and $4.99, \mathrm{~d}, J=17.2 \mathrm{~Hz}$, $\mathrm{H}_{2}-2 ; 5.39$ and 4.98 , each br s, $\mathrm{H}_{2}-3 ; 4.03$ and $3.93, \mathrm{~d}, J=15.2 \mathrm{~Hz}$, $\mathrm{H}_{2}-15$ and $1.13, \mathrm{~s}, \mathrm{H}_{3}-14$ ) displayed characteristic low-field and high-field signals of an elemane-type framework, which is a common sesquiterpene skeleton encountered in Centaurea genus (Cardona et al., 1997; Karamenderes et al., 2007b). The splitting patterns of the $A B$ system doublets deriving from the hydroxymethyl residue $\left(\delta_{\mathrm{H}} 4.03\right.$ and $\left.3.93, J_{\mathrm{AB}}=15.2, \mathrm{H}_{2}-15\right)$ and the methyl signal $\left(\delta_{\mathrm{H}} 1.13, \mathrm{~s}, \mathrm{H}_{3}-14\right)$ suggested their attachments to quaternary carbons, whereas the ${ }^{2} J_{\mathrm{C}-\mathrm{H}}$ correlations between $\mathrm{H}_{2}-15$ and $\mathrm{C}-4\left(\delta_{\mathrm{C}}\right.$ 146.2), and $\mathrm{H}_{3}-14$ and $\mathrm{C}-10\left(\delta_{\mathrm{C}} 43.0\right)$ in the HMBC spectrum put 
forward the positions of this two groups. Also the allylic coupling between exomethylene protons at $\delta_{\mathrm{H}} 5.39$ and $4.98\left(\mathrm{H}_{2}-3\right)$ with $\mathrm{H}_{2^{-}}$ 15 in the COSY spectrum, and the long-range ${ }^{3} J_{\mathrm{C}-\mathrm{H}}$ correlations between $\mathrm{C}-3 / \mathrm{H}-5$ and $\mathrm{H}-15$; $\mathrm{C}-15 / \mathrm{H}-3$ and $\mathrm{H}-5$; $\mathrm{C}-5 / \mathrm{H}-3, \mathrm{H}-7$ and $\mathrm{H}_{3}-14$ confirmed their positions in accordance with the elemane structure.

The $\alpha$-methylene- $\gamma$-lactone system is a common structural feature for the sesquiterpenes isolated from the genus Centaurea (Bruno et al., 2013). In the case of compound 1, comparison of the ${ }^{1} \mathrm{H}$ and ${ }^{13} \mathrm{C}$ NMR spectra with previously reported spectroscopic data of related metabolites revealed that the low-field shift of the oxymethine proton assigned to $\mathrm{H}-6\left(\delta_{\mathrm{H}} 4.56\right)$ indicated an acylation at this position, compatible with the $6,12-\gamma$-lactone moiety. On the other hand, the high-field shift of the carbon resonance assigned to $\mathrm{C}-11\left(\delta_{C} 44.5\right)$ and the COSY correlations of $\mathrm{H}-7 \rightarrow \mathrm{H}-11 \rightarrow \mathrm{H}_{2}-13$ implied the saturation of the characteristic exocyclic double bond extending from lactone ring (C-11) (Matsuda et al., 2000). This prediction was subsequently confirmed by the heteronuclear longrange correlations of the methine $\left(\delta_{\mathrm{C}} 58.0\right.$ and $44.5, \mathrm{C}-7$ and $\mathrm{C}-11$, respectively) and carbonyl $\left(\delta_{\mathrm{C}} 176.8, \mathrm{C}-12\right)$ resonances with the methylene protons at $\delta_{\mathrm{H}} 3.66$ and 3.44 assigned to $\mathrm{H}_{2}-13$. Chemical shift of $\mathrm{H}_{2}-13$ also suggested its connection to an electron withdrawing group. In the $\mathrm{HMBC}$ spectrum, the long-range correlations between $C-2^{\prime} / C-5^{\prime}\left(\delta_{C} 72.0\right.$ and 57.1 , respectively) and $\mathrm{H}_{2}-13$ protons not only verified the presence of abovementioned electronegative group but also linkage site of the proline moiety.

The relative stereochemistry of $\mathbf{1}$ was proposed by analyzing the coupling constants and comparison of the spectroscopic data with previously reported similar metabolites. Evaluation of the other naturally occurring elemane-type sesquiterpenes reported from the genus Centaurea, $\mathrm{H}-7$ was readily assigned with $\alpha$-configuration (Bruno et al., 2013; Karamenderes et al., 2007b). Based on this postulation, H-6 must be $\beta$-oriented as the coupling constant suggested an antiperiplanar orientation $\left(J_{6,7}=11.6 \mathrm{~Hz}\right)$. Moreover, the coupling constant between $\mathrm{H}-6$ and $\mathrm{H}-5$ protons was also large $\left(J_{5,6}=12 \mathrm{~Hz}\right)$, indicating that $\mathrm{H}-5$ and $\mathrm{H}-6$ were trans-diaxially oriented. These results suggested that 1 had $\mathrm{H}-5(\alpha) / \mathrm{H}-6(\beta) / \mathrm{H}-$ $7(\alpha) / \mathrm{H}-8(\beta)$ configurations. On the basis of these findings, the structure of 1 was established as $13-N$-proline- $8 \alpha, 15$-dihydroxyelema-1,3-diene-6 $\alpha, 12$-olide, and named as $13-N$-proline melitensin in accordance with previously reported secondary metabolite melitensin (Bruno et al., 2013).

Compound 2 was isolated as a colorless gum. QTOF-MS spectra of 2 exhibited protonated and deprotonated molecular ion peaks for $[\mathrm{M}+\mathrm{H}]^{+}$and $[\mathrm{M}-\mathrm{H}]^{-}$at $\mathrm{m} / z 398.1655$ and 396.2018, respectively, in agreement with the molecular formula $\mathrm{C}_{20} \mathrm{H}_{31} \mathrm{NO}_{7}$, which was 18 amu greater than compound 1. The ${ }^{1} \mathrm{H}$ and ${ }^{13} \mathrm{C}$ NMR spectra of 2 revealed the similarity of structures when compared to those of $\mathbf{1}$. The spectroscopic assignment was completed comprehensively by examining COSY, HSQC and HMBC spectra. In the case of compound 2 the only difference observed was the high-field shift of a methine proton (ca. $0.7 \mathrm{ppm}$ ) and a carbon (ca. $10 \mathrm{ppm}$ ) signal assigned to $\mathrm{C}(\mathrm{H})-6\left(\delta_{\mathrm{H}} 3.90\right.$ and $\left.\delta_{\mathrm{C}} 70.5\right)$, and these observations suggested a free hydroxyl group at C-6. Additionally, 6 degrees of unsaturation deduced from the molecular formula revealed the monocyclic nature of the structure. All these data clearly proved the absence of $6,12-\gamma$-lactone ring in accordance with the aforementioned $18 \mathrm{amu}$ difference. The relative stereochemistry of compound $\mathbf{2}$ was based on 2D-NOESY data. Particularly, the strong NOESY correlation between $\mathrm{H}-6$ and $\mathrm{H}-11$ allowed us to locate $\mathrm{H}-11$ at $\beta$ face of the molecule.

Consequently, the structure of 2 was established as 13- $\mathrm{N}$-proline-6 $\alpha, 8 \alpha, 15$-trihydroxy elema-1,3-diene-12-oic acid.

To determine the absolute configuration of proline, compound 2 was taken into acidic hydrolysis study because of its higher quantity compared to $\mathbf{1}$. Treatment of $\mathbf{2}$ with $1 \%$ aqueous hydrochloric acid $(\mathrm{HCl})$ at room temperature liberated $\mathbf{6}$ and proline. Optical rotation measurement of purified proline made clear that its absolute configuration was $\mathrm{L}\left([\alpha]_{\mathrm{D}}^{20}-85\right.$, c. $\left.0.001, \mathrm{MeOH}\right)$ (Convention, 2005). Compound $\mathbf{1}^{\prime}$ 's proline residue was assumed as L by way of analogy with 2 , whereas the configuration of $\mathrm{H}-11$ in 1 was also proposed to be $\beta$ by means of same inference.

Molecular formula of 3 was determined as $\mathrm{C}_{20} \mathrm{H}_{28} \mathrm{O}_{7}$ due to the sodium adduct and deprotonated ion peaks at $\mathrm{m} / \mathrm{z} 403.1726$ $[\mathrm{M}+\mathrm{Na}]^{+}$and $379.1590[\mathrm{M}-\mathrm{H}]^{-}$obtained by QTOF-MS analyses. Close examination of the ${ }^{1} \mathrm{H},{ }^{13} \mathrm{C}-\mathrm{NMR}$ and HSQC spectra of $\mathbf{3}$ once again suggested an elemane-type structure $\left(\delta_{\mathrm{H}} 5.77\right.$, dd, $J=18$, $10.8 \mathrm{~Hz}, \mathrm{H}-1 ; 4.94, \mathrm{~d}, J=10.8 \mathrm{~Hz}$ and $4.92, \mathrm{~d}, J=18 \mathrm{~Hz}, \mathrm{H}_{2}-2 ; 5.35$ and 4.97, each br s, $\mathrm{H}_{2}-3 ; 4.01$ and $3.91, \mathrm{~d}, J=14.8 \mathrm{~Hz}, \mathrm{H}_{2}-15$ and $\left.1.21, \mathrm{~s}, \mathrm{H}_{3}-14\right)$. When compared to 1 and 2 , characteristic exocyclic methylene ( $\alpha$-methylene) protons were present as a pair of broad singlet signals at $\delta_{\mathrm{H}} 6.28$ and $5.70\left(\mathrm{H}_{2}-13\right)$ in the ${ }^{1} \mathrm{H}$ NMR spectrum. On the other hand loss of a methine group and presence of an olefinic carbon resonance referred to $C-11\left(\delta_{C} 140.8\right)$ were notable. The location of the exocyclic double bond was straightforwardly located by the long-range correlations between $\mathrm{H}_{2}-13$ protons and C-7, C-11 and C-12 ( $\delta_{C} 56.9,140.8$ and 170.4, respectively).

Subtraction of the 15 carbon resonances and proton signals referring to the elemane framework revealed additional resonances including an olefinic proton $\left(\delta_{\mathrm{H}} 6.30 ; \delta_{\mathrm{C}} 139.1 ; \mathrm{C}-3^{\prime}\right)$, a secondary methyl signal $\left(\delta_{\mathrm{H}} 1.97 ; \delta_{\mathrm{C}} 15.7 ; \mathrm{C}-4^{\prime}\right)$, an oxymethylene group $\left(\delta_{\mathrm{H}}\right.$ 4.16 and $\left.4.10 ; \delta_{C} 63.9 ; C-5^{\prime}\right)$ and two carbon resonances related to these groups (a carbonyl and an olefinic at $\delta_{C} 167.5$ and 133.6; C- $1^{\prime}$ and $\mathrm{C}-2^{\prime}$, respectively). The correlations between $\mathrm{H}-3^{\prime}$ and $\mathrm{H}-4^{\prime}$ $\left(J_{3^{\prime}, 4^{\prime}}=7.2 \mathrm{~Hz}\right)$ in the COSY spectrum and the allylic couplings observed for $J_{3^{\prime}, 5^{\prime}}$ and $J_{4^{\prime}, 5^{\prime}}$, (each $1.2 \mathrm{~Hz}$ ) were evident for the presence of (E)-2-hydroxymethyl-but-2-enoyl (syn. sarracenyl) (Gil et al., 1992) moiety, a common side chain encountered in Centaurea sesquiterpenes (Youssef, 1998).

When compared to $\mathbf{1}$ and 2, the low-field shift (ca $1.5 \mathrm{ppm}$ ) of the proton at $\delta_{\mathrm{H}} 5.53(\mathrm{~J}=11.2$ and $4.4 \mathrm{~Hz})$ assigned to the $\mathrm{H}-8$ was not only indicated an acylation at this position but also attachment of the side chain at C-8. The location of the 2-hydroxymethyl-but2-enoyl moiety was directly confirmed by the ${ }^{3} J_{\mathrm{C}-\mathrm{H}}$ correlation between $C-1^{\prime}\left(\delta_{C} 167.5\right)$ and $\mathrm{H}-8\left(\delta_{\mathrm{H}} 5.53\right)$ in the HMBC spectrum.

The relative configurations of the stereocenters in $\mathbf{3}$ were identical with those of $\mathbf{1}$. Analysis of the coupling constants between $\mathrm{H}-5 / \mathrm{H}-6\left(J_{5,6}=10.8 \mathrm{~Hz}\right), \mathrm{H}-6 / \mathrm{H}-7\left(J_{6,7}=10.4 \mathrm{~Hz}\right)$ and $\mathrm{H}-7 / \mathrm{H}-$ $8\left(J_{7,8}=11.2 \mathrm{~Hz}\right)$ suggested that $3 \mathrm{had} \mathrm{H}-5(\alpha) / \mathrm{H}-6(\beta) / \mathrm{H}-7(\alpha) / \mathrm{H}-8(\beta)$ configurations. Based on these findings, the structure of 3 was established as $8 \alpha-O$-[ $2^{\prime}$-(hydroxymethyl)-but-2'-enoyl]-6 $\alpha, 15$ dihydroxyelema-1,3,11(13)-trien-12-oic acid.

QTOF-MS analysis of 4 suggested a molecular formula of $\mathrm{C}_{16} \mathrm{H}_{24} \mathrm{O}_{6}\left(\mathrm{~m} / z\right.$ 335.1466 [M+Na] $\left.{ }^{+}\right)$. 1D and 2D-NMR spectra of 4 revealed one carbonyl $\left(\delta_{C}\right.$ 168.5), two quaternary carbons (including one olefinic at $\left.\delta_{C} 139.8\right)$, one aldehyde $\left(\delta_{H} 9.31 ; \delta_{C} 204.9\right)$, one exocyclic methylene as a pair of broad singlet signals $\left(\delta_{\mathrm{H}} 6.33\right.$ and $\left.5.70 ; \delta_{C} 130.0\right)$, three oxymethine groups $\left(\delta_{H} 4.07,3.87\right.$ and 3.28; $\delta_{\mathrm{C}} 68.1,71.4$ and 78.3$)$, a singlet proton signal attributed to a methoxy group $\left(\delta_{\mathrm{H}} 3.74,3 \mathrm{H} ; \delta_{\mathrm{C}} 52.0\right)$, three methines $\left(\delta_{\mathrm{H}} 2.23,2.19\right.$ and 2.19), three methylene groups (resonating between $\delta_{\mathrm{H}} 1.09$ and 2.27; $\delta_{\mathrm{C}} 46.5,28.8$ and 25.4$)$ and a methyl $\left(\delta_{\mathrm{H}} 0.95,3 \mathrm{H} ; \delta_{\mathrm{C}} 12.6\right)$.

After subtraction of the methoxy group, the presence of 15 carbon resonances together with overall spectral profile suggested another sesquiterpene structure. The proton and carbon data secured by COSY, HSQC and HMBC spectra revealed a different core structure consistent with an eudesmane framework (Saroglou et al., 2005) (Fig. 2). Comparison of the spectroscopic data with those reported in the literature proved the presence of an aldehyde group at C-15 $\left(\delta_{\mathrm{H}} 9.31, \mathrm{~d} ; \delta_{\mathrm{C}} 204.9\right)$ rather than a primary alcohol. 

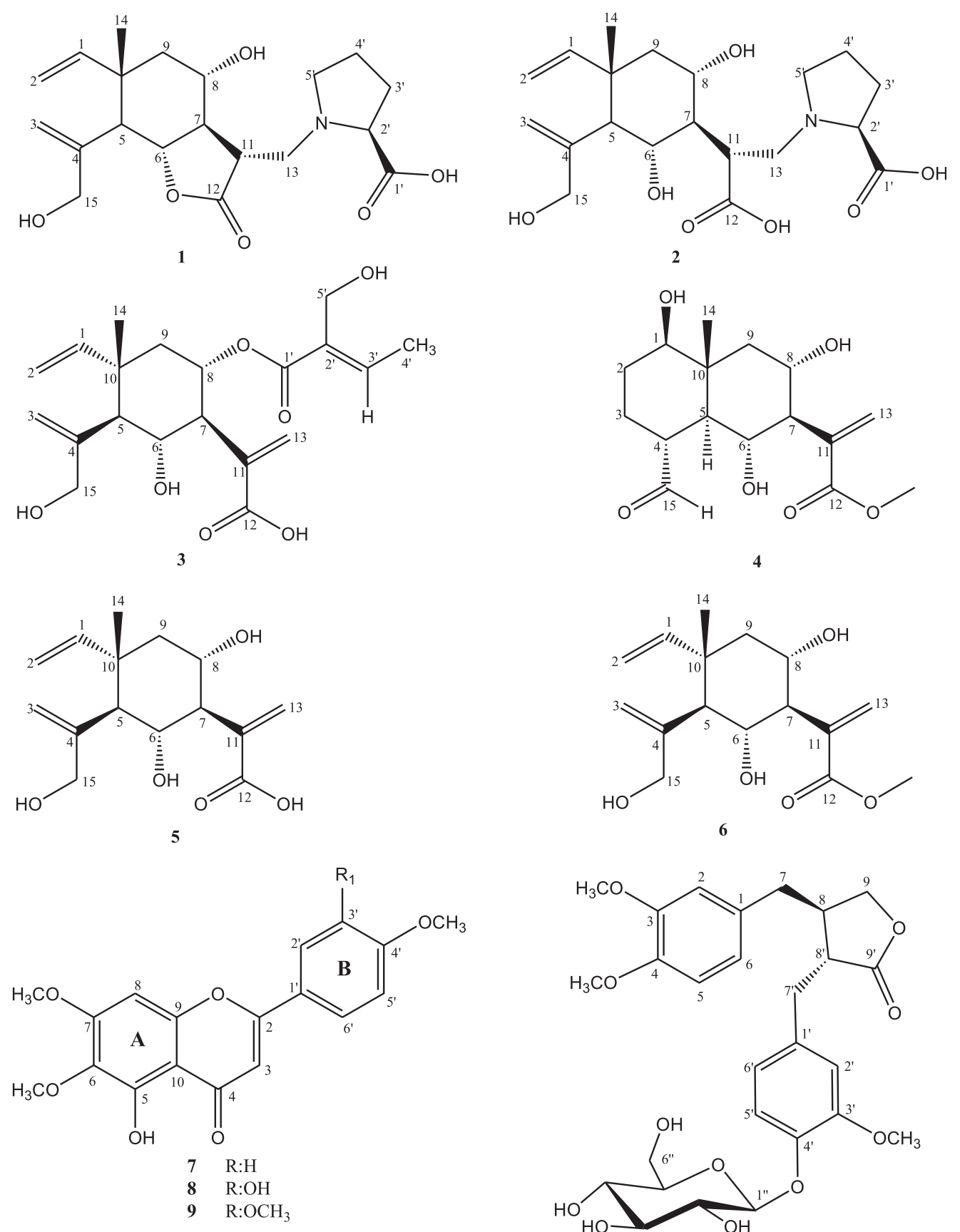<smiles>COc1ccc(O)c(OC)c1</smiles><smiles>COc1ccc(C[C@H]2COC(=O)[C@@H]2Cc2ccc(Oc3ccc(OC)c(OC)c3)c(OC)c2)cc1O</smiles><smiles>COc1cc(/C=C/CO)cc(OC)c1OC</smiles>

Fig. 1. Structures of compounds $\mathbf{1}-\mathbf{1 2}$. 

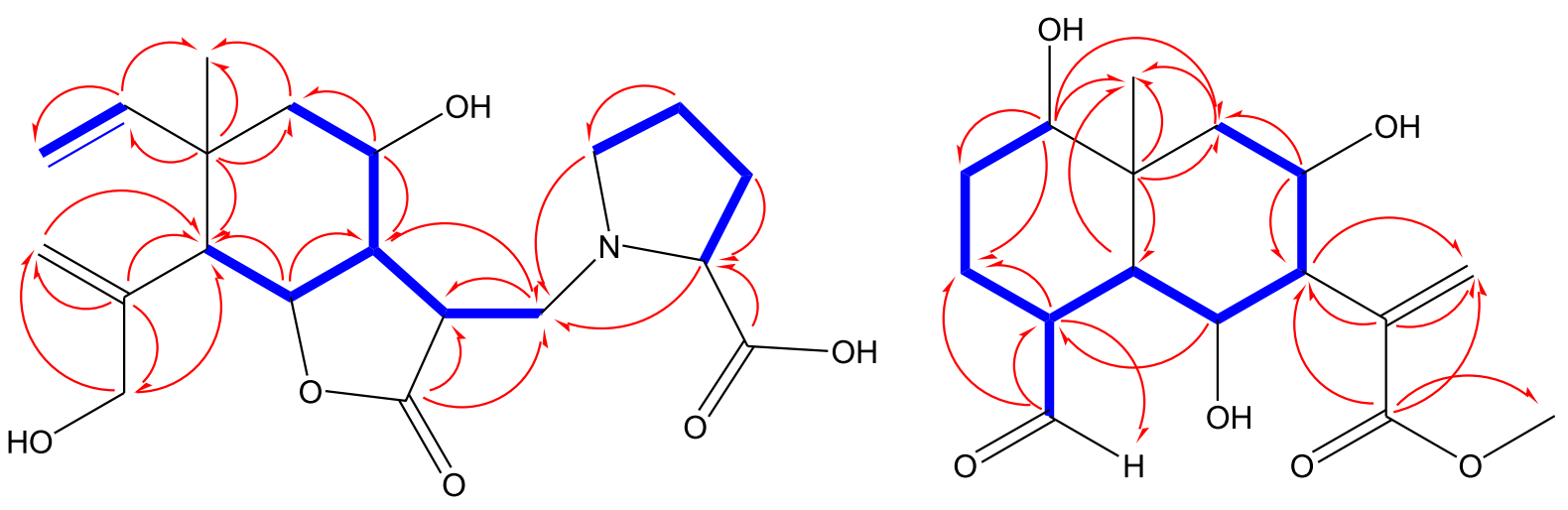

COSY correlations

Key HMBC's (from $\mathrm{C}$ to $\mathrm{H}$ )

Fig. 2. COSY and key HMBC correlations of compounds $\mathbf{1}$ and 4.

The $\alpha$ configuration of $\mathrm{C}-15$ was determined based on the up-field shift of the $\mathrm{H}-15$ and its coupling constant with $\mathrm{H}-4\left(J_{4,15}=5.2 \mathrm{~Hz}\right)$. In the case of $15 \beta-\mathrm{CHO}$, the aldehyde proton was reported to be a broad singlet resonating at about $\delta_{\mathrm{H}}$ 9.91-9.94 (Bruno et al., 2013). Presence of a free $\beta$-oriented hydroxyl group at $\mathrm{C}-1$ was also ensured by comparing the spectral data of $\mathbf{4}$ with the literature (Karioti et al., 2002; Saroglou et al., 2005; Skaltsa et al., 2000).

As in 3, compound 4 provided characteristic signals for an acrylic acid moiety extending from C-7 and a free hydroxyl group at C-6 instead of a lactone ring. A weak allylic coupling between exocyclic methylene protons of $\mathrm{C}-13$ and $\mathrm{H}-7$ in the COSY spectrum, and the long-range correlations from $\mathrm{C}-12$ to $\mathrm{H}-7$ and $\mathrm{H}_{2}-13, \mathrm{C}-11$ to $\mathrm{H}-7$ and $\mathrm{H}_{2}-13$, and $\mathrm{C}-13$ to $\mathrm{H}-7$ in the $\mathrm{HMBC}$ spectrum were evident for the acrylic acid residue's position. Additionally, ${ }^{3} J_{C-H}$ correlation between $C-12\left(\delta_{C} 168.5\right)$ and the methyl signal at $\delta_{H} 3.74$ revealed the ester nature of $\mathbf{4}$ (Skaltsa et al., 2000).

The relative stereochemistry of $\mathbf{4}$ was resolved on the basis of coupling constant analysis: $\left[\mathrm{H}-5 / \mathrm{H}-6\left(\mathrm{~J}_{5,6}=10.8 \mathrm{~Hz}\right), \mathrm{H}-6 / \mathrm{H}-7\right.$ $\left(J_{6,7}=10.4 \mathrm{~Hz}\right)$ and $\left.\mathrm{H}-7 / \mathrm{H}-8\left(J_{7,8}=10.4 \mathrm{~Hz}\right)\right]$ and comparison of the spectroscopic data with relevant structures establishing the configurations as $\mathrm{H}-5(\alpha) / \mathrm{H}-6(\beta) / \mathrm{H}-7(\alpha) / \mathrm{H}-8(\beta)$ (Karioti et al., 2002). Based on these findings, the structure of $\mathbf{4}$ was determined as

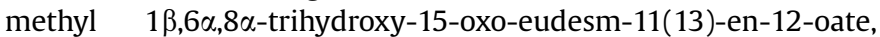
the deacyl derivative of 4-epi-carmanin previously reported from Centaurea achaia (Skaltsa et al., 2000).

Secondary metabolites of Centaurea species are mainly sesquiterpene lactones with guaiane, germacrane, eudesmane and elemane skeletons (Bruno et al., 2013; Cardona et al., 1997; Karamenderes et al., 2007b; Karioti et al., 2002; Skaltsa et al., 2000). As a member of the genus Centaurea, C. polyclada afforded distinctive sesquiterpene structures. Elemanolides obtained from Centaurea species are generally melitensin, dehydromelitensin and their derivatives with different ester chains (Bruno et al., 2013).

In regards to Asteraceae family, a few addition products of aminoacids to the conjugated double bond of sesquiterpene lactones have been reported and the $13-\mathrm{N}$-substitued sesquiterpene derivatives appeared to be the characteristic compounds for Saussurea species. Saussureamines (A, B, E) from S. lappa (Matsuda et al., 2000) and pulchellamine $C$ from $S$. pulchella (Yang et al., 2008) are the significant representatives of sesquiterpene-amino acid conjugates having guaiane, germacrane and eudesmane skeletons and L-proline as amino acid residue. Several derivatives were also reported from different Asteraceae members as Inula helenium (Zaima et al., 2014), Ixeris dentata (Cha et al., 2012) and Scorzonera divaritica (Yang et al., 2016). Only a germacrane derivative, namely onopordopicrin-valine dimeric adduct from Centaurea aspera
(Marco et al., 2005) was reported in the genus Centaurea.

To the best of our knowledge, the previously undescribed compounds, 13- $N$-proline melitensin (1) and 13- $N$-proline$6 \alpha, 8 \alpha, 15$-trihydroxyelema-1,3-dien-12-oic acid (2), are very unusual representatives of a group of sesquiterpenes containing amino acid residues, namely L-proline. Elemane-amino acid conjugates were encountered for the first time in nature. $8 \alpha-O-\left[2^{\prime}-\right.$ (hydroxymethyl)-but-2'-enoyl]-6 $\alpha, 15$-dihydroxyelema-1,3,11(13)trien-12-oic acid (3) and methyl 1 $\beta, 6 \alpha, 8 \alpha$-trihydroxy-15-oxoeudesm-11(13)-en-12-oate (4) are also previously undescribed natural products with elemane and eudesmane-type sesquiterpene frameworks. On the other hand, $6 \alpha, 8 \alpha, 15$-trihydroxyelema1,3,11(13)-trien-12-oic acid (5) is a commercially available elemane derivative with no report from natural sources; therefore, it should be regarded as a new natural product.

\section{Experimental}

\subsection{General experimental procedures}

IR spectra were obtained on a Perkin Elmer Spectrum 100 FT-IR spectrometer. Mass spectra analysis was carried out on ThermoScientific TSQ Quantum Access Max LC-MS/MS equipped with an ESI source. High Resolution Mass spectra were obtained on Agilent 6200 Series TOF and 6500 Series QTOF-MS system equipped with an ESI source. Optical rotation measurements were done on a Perkin Elmer Model-351 polarimeter in $\mathrm{MeOH}$ at $20^{\circ} \mathrm{C}$. $1 \mathrm{D}$ and 2D (COSY, HMBC, HSQC and NOESY) NMR spectra were recorded on Varian Oxford AS400 spectrometer with TMS as internal standard at room temperature. 2D NMR spectra were run using standard Varian pulse programs. Column chromatography was carried out on silica gel 60 (40-63 mu-Merck), Sephadex LH-20 (GE Healthcare) and Lichroprep RP-C18 (25-40 m $\mu$, Merck) using analytical grade purity solvents (Merck and Sigma). TLC analyses were carried out on silica gel $60 \mathrm{~F}_{254}$ and RP-C18 $\mathrm{F}_{254 \mathrm{~s}}$ (Merck) pre-coated aluminum plates. Compounds were detected by UV (244-366 nm) and vanillin/ $\mathrm{H}_{2} \mathrm{SO}_{4}$ reagent followed by heating. Spraying with ninhydrin reagent followed by heating was used to detect the amino acid residue.

\subsection{Plant material}

Centaurea polyclada DC. (Asteraceae) was collected from the roadside of Kayadibi village district, Izmir, Turkey in June 2010 ( $500 \mathrm{~m}, 38^{\circ} 30^{\prime} 21.0^{\prime \prime} \mathrm{N}, 27^{\circ} 14^{\prime} 35.6^{\prime \prime} \mathrm{E}$ ). The plant was confirmed by Assoc. Prof. Serdar Gokhan Senol from Section of Botany, 
Department of Biology, Faculty of Science, Ege University and a voucher specimen (IZEF-5914) was deposited in the Herbarium of Ege University, Faculty of Pharmacy, Izmir, Turkey.

\subsection{Extraction and isolation}

Air-dried and grounded aerial parts of the plant $(2.2 \mathrm{~kg})$ were extracted with $n$-hexane, chloroform $\left(\mathrm{CHCl}_{3}\right)$ and methanol $(\mathrm{MeOH})(3 \times 5 \mathrm{~L}$, each) by sonification for $24 \mathrm{~h}$ and then filtered. The extracts were separately evaporated under reduced pressure to dryness and yielded $44.3 \mathrm{~g} n$-hexane, $35.9 \mathrm{~g} \mathrm{CHCl}_{3}$ and $121.3 \mathrm{~g}$ $\mathrm{MeOH}$ extracts. Dried $\mathrm{MeOH}$ extract was suspended in water and partitioned with $n$-butanol $(n-\mathrm{BuOH})\left(\mathrm{H}_{2} \mathrm{O}: n-\mathrm{BuOH} ; 1: 7\right)$ and yielded $34.5 \mathrm{~g} n$-BuOH extract.

$\mathrm{CHCl}_{3}$ extract ( $30 \mathrm{~g}$ ) was dry loaded and chromatographed over RP-C18 column (200 g) $\left(\mathrm{H}_{2} \mathrm{O}: \mathrm{MeOH}, 80: 20\right.$ to $0: 100 ; 10 \%$ decreasing polarity, each $1 \mathrm{~L}$ ) and 30 main fractions (Frs 1-30) were collected. Based on TLC profiles, 6 main fractions; C1 (Frs. 3-5), C2 (Frs. 8-9), C3 (Frs. 10-12), C4 (Frs. 14-18), C5 (Frs. 19-23) and C6 (Frs. 24-27) were selected for further purification.

Fraction C1 (827 mg) was subjected to Sephadex LH-20 column (80 g) using $100 \% \mathrm{MeOH}$ and afforded 60 subfractions. Frs. C2/ 16-27 (335 mg) chromatographed over silica gel column (si-gel) $(15 \mathrm{~g})$ using $\mathrm{CHCl}_{3}: \mathrm{MeOH}: \mathrm{H}_{2} \mathrm{O}(90: 10: 1,200 \mathrm{ml} ; 85: 15: 0.5$ and $80: 20: 2,100 \mathrm{ml} \mathrm{each})$ and subfractions $17-28(143 \mathrm{mg})$ were rechromatographed over si-gel with EtOAc: $\mathrm{MeOH}: \mathrm{H}_{2} \mathrm{O}$ (100:5:0.5, isocratic, $300 \mathrm{ml})$. Subfractions $61-75(76 \mathrm{mg})$ were further purified using $\mathrm{CHCl}_{3}: \mathrm{MeOH}: \mathrm{H}_{2} \mathrm{O}$ (90:10:1, isocratic, $100 \mathrm{ml}$ ) to afford 4 (31 mg).

Fraction C2 (970 mg) was chromatographed over si-gel (25 g) using $\mathrm{CHCl}_{3}: \mathrm{MeOH}: \mathrm{H}_{2} \mathrm{O}$ (90:10:1, 80:20:1 and 70:30:3, $200 \mathrm{ml}$ each) and 95 sub-fractions were obtained. Frs. 3-11 (285) were subjected to si-gel (10 g) with $n$-hexane:EtOAc (60:40 to 50:50, with $2 \%$ increasing polarity, $100 \mathrm{ml}$ each). Subfractions 94-156 (137 mg) were re-chromatographed over si-gel $\left(\mathrm{CHCl}_{3}: \mathrm{MeOH}: \mathrm{H}_{2} \mathrm{O}\right.$, 90:10:0.5, isocratic, $100 \mathrm{ml}$ ) and $\mathbf{5}(38 \mathrm{mg})$ was obtained.

Fraction C3 (1979 mg) was subjected to si-gel (35 g) with $\mathrm{CHCl}_{3}: \mathrm{MeOH}: \mathrm{H}_{2} \mathrm{O}$ (90:10:1, $400 \mathrm{ml}$ and 80:20:1, $\left.200 \mathrm{ml}\right)$ and subfraction 39-66 (772 mg) were purified with si-gel (EtOAc:$\mathrm{MeOH}: \mathrm{H}_{2} \mathrm{O}, 100: 5: 1$, isocratic, $\left.200 \mathrm{ml}\right)$ to afford $10(640 \mathrm{mg})$.

Fraction C4 (2685 mg) was chromatographed over si-gel column $(40 \mathrm{~g})$ using $\mathrm{CHCl}_{3}: \mathrm{MeOH}: \mathrm{H}_{2} \mathrm{O}$ (90:10:1, $400 \mathrm{ml}$ and 80:20:1, $200 \mathrm{ml}$ ) and finally treated with $\mathrm{MeOH}$. $\mathrm{MeOH}$ fraction (212 mg) was further purified with $\mathrm{CHCl}_{3}: \mathrm{MeOH}: \mathrm{H}_{2} \mathrm{O}(90: 10: 1,200 \mathrm{ml}$ and 85:15:0.5, $300 \mathrm{ml}$ ) over si-gel (15 g) and $\mathbf{3}$ (59 $\mathrm{mg}$ ) was obtained.

A small amount of residue was observed in the fraction $\mathrm{C} 5$. Insoluble part (788 $\mathrm{mg}$ ) was centrifuged and chromatographed over si-gel column (15 g) using $\mathrm{CHCl}_{3}(300 \mathrm{ml})$ to afford 8 (247 mg). The soluble portion (1300 mg) was chromatographed over si-gel (25 g) with $\mathrm{CHCl}_{3}: \mathrm{MeOH}: \mathrm{H}_{2} \mathrm{O}$ (90:10:1, $300 \mathrm{ml}$ and 70:30:3, $100 \mathrm{ml}$ ) and subfractions 5-28 (730 $\mathrm{mg})$ were subjected to Sephadex LH-20 column (50 g) using $\mathrm{MeOH}(500 \mathrm{ml})$. Subfractions 21-31 (51 mg) were further purified over si-gel (10 g) using $\mathrm{CHCl}_{3}$ $(100 \mathrm{ml})$ to yield $\mathbf{9}(9 \mathrm{mg})$.

Fraction C6 (1.4 g) was subjected to Sephadex LH-20 column $(80 \mathrm{~g})$ with $\mathrm{MeOH}(600 \mathrm{ml})$ and 120 subfractions were obtained. Subfractions 84-120 (78 mg) were chromatographed over si-gel column $\left(\mathrm{CHCl}_{3}, 200 \mathrm{ml}\right)$ and yielded $7(35 \mathrm{mg})$.

$n$-BuOH extract (30 g) was dry loaded and chromatographed over RP-C18 column (200 g) using $\mathrm{H}_{2} \mathrm{O}: \mathrm{MeOH}$ (100:0 to 0:100; $10 \%$ decreasing polarity, each $1 \mathrm{~L}$ ). 30 main fractions (Frs 1-30) were collected and based on TLC profiles, 2 main fractions; B1 (Frs. 2-6) and B2 (Frs. 7-8) were selected for further purification.

Fraction B1 (6 g) was chromatographed over RP-C18 (100 g) using $\mathrm{H}_{2} \mathrm{O}(500 \mathrm{ml})$ and 100 fractions were collected.
Fractions B1/30-39 (585 mg) were chromatographed over si-gel (45 g) with $\mathrm{CHCl}_{3}: \mathrm{MeOH}: \mathrm{H}_{2} \mathrm{O}$ (70:30:3, 61:32:7, 64:50:10, $500 \mathrm{ml}$ each) and subfractions $165-224$ were re-chromatographed over sigel (10 g) using $\mathrm{CHCl}_{3}: \mathrm{MeOH}: \mathrm{H}_{2} \mathrm{O}(70: 30: 3$, isocratic, $200 \mathrm{ml})$ to afford 1 (13 mg). Subfractions 225-261 (102 mg) were further purified with $\mathrm{CHCl}_{3}: \mathrm{MeOH}: \mathrm{H}_{2} \mathrm{O}(61: 32: 7$, isocratic, $300 \mathrm{ml})$ and yielded 2 (23 mg).

Fractions B1/40-57 (436 mg) were subjected to Sephadex LH-20 column (40 g) using $\mathrm{MeOH}$ (500 ml). Subfractions 28-40 (153 mg) were dry-loaded and chromatographed over si-gel (10 g) with $\mathrm{CHCl}_{3}: \mathrm{MeOH}: \mathrm{H}_{2} \mathrm{O}$ (80:20:1, $100 \mathrm{ml} ; 80: 20: 2,400 \mathrm{ml}$ and 70:30:3, $100 \mathrm{ml}$ ) and 80 fractions were collected. Subfractions 20-28 (10 $\mathrm{mg}$ ) and 45-80 (34 mg) were separately purified with $\mathrm{CHCl}_{3}: \mathrm{MeOH}: \mathrm{H}_{2} \mathrm{O}(80: 20: 1$, isocratic, $100 \mathrm{ml})$ to afford $11(7 \mathrm{mg})$ and $6(19 \mathrm{mg})$ respectively.

Fraction B2 (1375 mg) was chromatographed over Sephadex LH20 column $(80 \mathrm{~g})$ with $\mathrm{MeOH}(500 \mathrm{ml})$ and afforded 150 subfractions. Fractions $19-39$ (830 mg) were subjected to RP-C18 column (10 g) using $\mathrm{H}_{2} \mathrm{O}: \mathrm{MeOH}$ (100:0 to 80:20, 2\% decreasing polarity, $100 \mathrm{ml}$ each). The insoluble portion of subfractions 107-145 was centrifuged and 12 (169 mg) was obtained.

\subsection{Acid treatment of $13-N$-proline- $6 \alpha, 8 \alpha, 15$-trihydroxyelema-1,3- dien-12-oic acid (2)}

Acid treatment of $\mathbf{2}(15 \mathrm{mg}$ ) with $1 \%$ aqueous hydrochloric acid $(\mathrm{HCl}, 10 \mathrm{ml})$ at room temperature affording a mixture (Matsuda et al., 2000). An aliquot of the reaction mixture was subjected to normal phase silica TLC ( $n$-BuOH:Acetic acid: $\left.\mathrm{H}_{2} \mathrm{O}, 3: 1: 1\right)$ to detect the amino acid by Ninhydrin reagent followed by heating. After verifying the presence of proline, the mixture was dried and subjected to silica gel column ( $10 \mathrm{~g})$ with $\mathrm{CHCl}_{3}: \mathrm{MeOH}: \mathrm{H}_{2} \mathrm{O}(70: 30: 3$ and 61:32:7100 ml each). Subfractions 39-52 were rechromatographed over Sephadex LH-20 (10 g) using $\mathrm{MeOH}$ $(100 \mathrm{ml})$ to afford proline $(4 \mathrm{mg})$. Optical rotation measurement verified the amino acid residue as L-proline $\left([\alpha]_{\mathrm{D}}^{20}-85\right.$, c. 0.001 , $\mathrm{MeOH}$ ) (Convention, 2005).

\subsection{Compound characterization}

13- $N$-proline melitensin (1): Yellowish gum; $[\alpha]_{D}^{20}-17.5$ (c. 0.005 , $\mathrm{MeOH}) ;{ }^{1} \mathrm{H}$ NMR $\left(\mathrm{CD}_{3} \mathrm{OD}, 400 \mathrm{MHz}\right)$ and ${ }^{13} \mathrm{C} \mathrm{NMR}\left(\mathrm{CD}_{3} \mathrm{OD}\right.$, $100 \mathrm{MHz}$ ) data: see Tables 1 and 2; QTOF-MS $m / z=380.2028$ $[\mathrm{M}+\mathrm{H}]^{+}$(calcd. for $\mathrm{C}_{20} \mathrm{H}_{30} \mathrm{NO}_{6}: 380.2073$, positive mode) and 378.1921 [M-H] $]^{-}$(calcd. for $\mathrm{C}_{20} \mathrm{H}_{28} \mathrm{NO}_{6}$ : 378.1917, negative mode).

$13-N$-proline-6 $\alpha, 8 \alpha, 15$-trihydroxyelema-1,3-dien-12-oic acid (2): Colorless gum; $[\alpha]_{D}^{20}-11.3$ (c. 0.008, MeOH); IR (KBr) 3389, 2929, 1590, 1411, 1339, 1208, 1135, 1049, $1008 \mathrm{~cm}^{-1} ;{ }^{1} \mathrm{H}$ NMR $\left(\mathrm{CD}_{3} \mathrm{OD}, 400 \mathrm{MHz}\right)$ and ${ }^{13} \mathrm{C}$ NMR $\left(\mathrm{CD}_{3} \mathrm{OD}, 100 \mathrm{MHz}\right)$ data: see Tables 1 and 2; QTOF-MS $m / z=398.1655[\mathrm{M}+\mathrm{H}]^{+}$(calcd. for $\mathrm{C}_{20} \mathrm{H}_{32} \mathrm{NO}_{7}$ : 398.2179, positive mode) and 396.2018 [M-H] ${ }^{-}$(calcd. for $\mathrm{C}_{20} \mathrm{H}_{30} \mathrm{NO}_{7}$ : 396.2022, negative mode).

$8 \alpha-O-\left[2^{\prime}\right.$-(hydroxymethyl)-but-2'-enoyl]-6$\alpha, 15-$ dihydroxyelema-1,3,11(13)-trien-12-oic acid (3): Yellowish gum; $[\alpha]_{\mathrm{D}}^{20}+27$ (c. 0.003, MeOH); IR (KBr) 3405, 2931, 1702, 1396, 1238, $1165,1052,1002,915 \mathrm{~cm}^{-1}$; ${ }^{1} \mathrm{H}$ NMR $\left(\mathrm{CD}_{3} \mathrm{OD}, 400 \mathrm{MHz}\right)$ and ${ }^{13} \mathrm{C}$ NMR ( $\mathrm{CD}_{3} \mathrm{OD}, 100 \mathrm{MHz}$ ) data: see Tables 1 and 2; QTOF-MS m/ $z=403.1726[\mathrm{M}+\mathrm{Na}]^{+}$(calcd. for $\mathrm{C}_{20} \mathrm{H}_{28} \mathrm{O}_{7} \mathrm{Na}$ : 403.1733, positive mode) and 379.1590 [M-H] ${ }^{-}$(calcd. for $\mathrm{C}_{20} \mathrm{H}_{27} \mathrm{O}_{7}$ : 379.1757 , negative mode).

Methyl 1 $1,6 \alpha, 8 \alpha$-trihydroxy-15-oxo-eudesm-11(13)-en-12-oate (4): Yellowish gum; $[\alpha]_{\mathrm{D}}^{20}-15$ (c. 0.003, MeOH); IR (KBr) 3405, 2949, 2353, 1712, 1626, 1442, 1334, 1262, 1198, 1167, $1033 \mathrm{~cm}^{-1} ;{ }^{1} \mathrm{H}$ NMR $\left(\mathrm{CD}_{3} \mathrm{OD}, 400 \mathrm{MHz}\right)$ and ${ }^{13} \mathrm{C}$ NMR $\left(\mathrm{CD}_{3} \mathrm{OD}, 100 \mathrm{MHz}\right)$ data: see Tables 1 and 2; QTOF-MS $m / z=335.1466[\mathrm{M}+\mathrm{Na}]^{+}$(calcd. for 
$\mathrm{C}_{16} \mathrm{H}_{24} \mathrm{O}_{6} \mathrm{Na}$ : 335.1471, positive mode).

$6 \alpha, 8 \alpha, 15$-trihydroxyelema-1,3,11(13)-trien-12-oic acid (5): Yellowish gum; ${ }^{1} \mathrm{H}$ NMR $\left(\mathrm{CD}_{3} \mathrm{OD}, 400 \mathrm{MHz}\right)$ and ${ }^{13} \mathrm{C} \mathrm{NMR}\left(\mathrm{CD}_{3} \mathrm{OD}\right.$, $100 \mathrm{MHz}$ ) data: see Tables 1 and 2; QTOF-MS $m / z=587.2832$ $[2 \mathrm{M}+\mathrm{Na}]^{+}$(calcd. for $\mathrm{C}_{30} \mathrm{H}_{44} \mathrm{O}_{10} \mathrm{Na}$ : 587.2832 , positive mode) and 281.1371 [M-H] $]^{-}$(calcd. for $\mathrm{C}_{15} \mathrm{H}_{21} \mathrm{O}_{5}$ : 281.1389, negative mode).

Methyl $6 \alpha, 8 \alpha, 15$-trihydroxyelema-1,3,11(13)-trien-12-oate (6): Yellowish gum; ${ }^{1} \mathrm{H}$ NMR $\left(\mathrm{CD}_{3} \mathrm{OD}, 400 \mathrm{MHz}\right)$ and ${ }^{13} \mathrm{C}$ NMR $\left(\mathrm{CD}_{3} \mathrm{OD}\right.$, $100 \mathrm{MHz}$ ) data: see Tables 1 and 2; QTOF-MS $\mathrm{m} / z=319.1518$ $[\mathrm{M}+\mathrm{Na}]^{+}$(calcd. for $\mathrm{C}_{16} \mathrm{H}_{24} \mathrm{O}_{5} \mathrm{Na}$ : 319.1521, positive mode).

\section{Acknowledgments}

The authors would like to thank Assoc. Prof. Serdar Gokhan Senol for authenticating the plant material, and Dr. Salih Gunnaz for all NMR measurements. This research project was supported by the Scientific Research Projects Directorate of Ege University (Project No: 12-ECZ-009).

\section{Appendix A. Supplementary data}

Supplementary data related to this article can be found at http:// dx.doi.org/10.1016/j.phytochem.2017.07.002.

\section{References}

Akkol, E.K., Arif, R., Ergun, F., Yesilada, E., 2009. Sesquiterpene lactones with antinociceptive and antipyretic activity from two Centaurea species. J. Ethnopharmacol. 122, 210-215.

Astari, K.A., Erel, S.B., Bedir, E., Karaalp, C., 2013. Secondary metabolites of Centaurea cadmea boiss. Rec. Nat. Prod. 7, 242-244.

Baykan-Erel, S., Bedir, E., Khan, I.A., Karaalp, C., 2010. Secondary metabolites from Centaurea ensiformis PH davis. Biochem. Syst. Ecol. 38, 1056-1058.

Bruno, M., Bancheva, S., Rosselli, S., Maggio, A., 2013. Sesquiterpenoids in subtribe Centaureinae (Cass.) dumort (tribe Cardueae, Asteraceae): distribution, ${ }^{13} \mathrm{C}$ NMR spectral data and biological properties. Phytochemistry 95, 19-93.

Cardona, L., Fernandez, I., Pedro, J.R., Vidal, R., 1992. Polyoxygenated terpenes and cyanogenic glucosides from Centaurea aspera var subinermis. Phytochemistry 31, 3507-3509.

Cardona, L., Garcia, B., Munoz, M.C., Navarro, F.I., Pedro, J.R., 1997. New sesquiterpene lactones and other constituents from Centaurea paui. Liebigs Ann-Recl. 527-532.

Cardona, M.L., Fernandez, I., Pedro, J.R., Perez, B., 1991. Sesquiterpene lactones and flavonoids from Centaurea aspera. Phytochemistry 30, 2331-2333.

Cha, M.R., Choi, C.W., Lee, J.Y., Kim, Y.S., Yon, G.H., Choi, S.U., Kim, Y.H., Ryu, S.Y., 2012. Two new amino acid-sesquiterpene lactone conjugates from Ixeris dentata. B Korean Chem. Soc. 33, 337-340.

Convention, U.S.P., 2005. USP 29, NF 24: the United States Pharmacopeia, the National Formulary. United States Pharmacopeial Convention.

Erel, S.B., Demirci, B., Demir, S., Karaalp, C., Baser, K.H.C., 2013. Composition of the essential oils of Centaurea aphrodisea, C. polyclada, C. athoa, C. hyalolepis and C. iberica. J. Essent. Oil Res. 25, 79-84.

Erel, S.B., Karaalp, C., Bedir, E., Kaehlig, H., Glasl, S., Khan, S., Krenn, L., 2011.
Secondary metabolites of Centaurea calolepis and evaluation of cnicin for antiinflammatory, antioxidant, and cytotoxic activities. Pharm. Biol. 49, 840-849.

Gil, R.R., Pacciaroni, A.D.V., Oberti, J.C., Diaz, J.G., Herz, W., 1992. A rearranged germacranolide and other sesquiterpene lactones from Stevia jujuyensis. Phytochemistry 31, 593-596.

Gulcemal, D., Alankus-Caliskan, O., Karaalp, C., Ors, A.U., Ballar, P., Bedird, E., 2010. Phenolic glycosides with antiproteasomal activity from Centaurea urvillei DC. subsp urvillei. Carbohyd Res. 345, 2529-2533.

Karamenderes, C., Bedir, E., Abou-Gazar, H., Khan, I.A., 2007a. Chemical constituents of Centaurea cadmea. Chem. Nat. Comp. 43, 694-695.

Karamenderes, C., Bedir, E., Pawar, R., Baykan, S., Khan, K.A., 2007b. Elemanolide sesquiterpenes and eudesmane sesquiterpene glycosides from Centaurea hierapolitana. Phytochemistry 68, 609-615.

Karioti, A., Skaltsa, H., Lazari, D., Sokovic, M., Garcia, B., Harvala, C., 2002. Secondary metabolites from Centaurea deusta with antimicrobial activity. Z Naturforsch C 57, 75-80.

Konuklugil, B., Bahadir, O., 2004. Phenylpropanoid glycosides from Linum olympicum (Linaceae). Turk J. Chem. 28, 741-744.

Liu, S.K., Que, S., Cheng, W., Zhang, Q.Y., Liang, H., 2013. Chemical constituents from whole plants of Carduus acanthoides. Zhongguo Zhong Yao Za Zhi 38 2334-2337.

Marco, J.A., Sanz-Cervera, J.F., Yuste, A., Sancenon, F., Carda, M., 2005. Sesquiterpenes from Centaurea aspera. Phytochemistry 66, 1644-1650.

Matsuda, H., Kageura, T., Inoue, Y., Morikawa, T., Yoshikawa, M., 2000. Absolute stereostructures and syntheses of saussureamines A, B, C, D and E, amino acidsesquiterpene conjugates with gastroprotective effect, from the roots of Saussurea lappa. Tetrahedron 56, 7763-7777.

Ozcelik, B., Gurbuz, I., Karaoglu, T., Yesilada, E., 2009. Antiviral and antimicrobial activities of three sesquiterpene lactones from Centaurea solstitialis L. ssp solstitialis. Microbiol. Res. 164, 545-552.

Salan, U., Topçu, G., Öksüz, S., 2001. Flavonoids of Centaurea kilaea and C. salonitana. J. Fac. Pharm. Istanb. 34, 55-61.

Saroglou, V., Karioti, A., Demetzos, C., Dimas, K., Skaltsa, H., 2005. Sesquiterpene lactones from Centaurea spinosa and their antibacterial and cytotoxic activities. J. Nat. Prod. 68, 1404-1407.

Shoeb, M., Rahman, M.M., Nahar, L., Delazar, A., Jaspars, M., MacManus, S.M., Sarker, S.D., 2004. Bioactive lignans from the seeds of Centaurea macrocephala. DARU 12, 87-93.

Skaltsa, H., Lazari, D., Garcia, B., Pedro, J.R., Sokovic, M., Constantinidis, T., 2000. Sesquiterpene lactones from Centaurea achaia, a Greek endemic species: antifungal activity. Z Naturforsch C 55, 534-539.

Skaltsa, H., Lazari, D., Georgiadou, E., Kakavas, S., Constantinidis, T., 1999. Sesquiterpene lactones from Centaurea species: C. thessala subsp drakiensis and C. attica subsp attica. Planta Med. 65, 393-393.

Uysal, T., 2012. Centaurea. In: Guner, A., Aslan, S., Ekim, T., Vural, M., Babac, M.T. (Eds.), Türkiye Bitkileri Listesi (Damarlı Bitkiler). Nezahat Gökyiğit Botanik Bahçesi ve Flora Araştırmaları Derneği Yayını, Istanbul, pp. 127-140.

Wagenitz, G., 1975. Centaurea L. In: Davis, P.H. (Ed.), Flora of Turkey and the East Aegean Islands, vol. V. Edinburgh University Press, pp. 465-585.

Yang, M.C., Choi, S.U., Choi, W.S., Kim, S.Y., Lee, K.R., 2008. Guaiane sesquiterpene lactones and amino acid-sesquiterpene lactone conjugates from the aerial parts of Saussurea pulchella. J. Nat. Prod. 71, 678-683.

Yang, Y.J., Yao, J., Jin, X.J., Shi, Z.N., Shen, T.F., Fang, J.G., Yao, X.J., Zhu, Y., 2016. Sesquiterpenoids and tirucallane triterpenoids from the roots of Scorzonera divaricata. Phytochemistry 124, 86-98.

Youssef, D.T.A., 1998. Sesquiterpene lactones of Centaurea scoparia. Phytochemistry 49, 1733-1737.

Zaima, K., Wakana, D., Demizu, Y., Kumeta, Y., Kamakura, H., Maruyama, T. Kurihara, M., Goda, Y., 2014. Isoheleproline: a new amino acid-sesquiterpene adduct from Inula helenium. J. Nat. Med-Tokyo 68, 432-435. 